\title{
Transformational leadership in Government secondary schools in Zimbabwe with special reference to Bulawayo
}

\author{
Lillie Beth Hadebe: \\ Ce [Uz], Bed [Uz], Med [Uz], Pgdmgt [Nust]. Zimbabwe Open University. Bulawayo
}

\begin{abstract}
The study sought to explore the extent to which transformational leadership could be applied in government secondary schools. The main aim was to establish how transformational leadership could boost productivity in government secondary schools. The study was carried out in government secondary schools in Bulawayo. Only schools' performance at O'level was used as a measure of academic performance of the schools. The sample was made up of 215 teachers drawn from Bulawayo secondary schools, 15 heads of schools, 5 District Officers and other key informants in the education system like BSPZ co-coordinators and the newly appointed secondary school inspectors. Also included in the sample were the Provincial Director, two Deputy Provincial Directors, and Education Officers; Examinations and Planning. Document analysis, observation, questionnaire, interviews and focus group discussions were used to collect data under the following themes; transformational leadership and transactional leadership, transformational leadership and the concepts of change, motivation, organizational culture and performance. All the respondents believed that heads of schools could use transformational leadership to create competitive advantage and uniqueness of schools, yet the issue of how policy could be successfully woven into heads' plans remained debatable. The study recommended that schools as business organizations needed leaders who clearly understood their role in the school production process.
\end{abstract}

Key Terms; transformational leadership, leadership, management

\section{Background of the study}

On April 1980, Zimbabwe gained its political independence from the British rule. Under the colonial British rule education system was for all intents and purposes capitalist oriented. This was a deliberate move put in place so as to promote and sustain white supremacy at the expense of black advancement, development and empowerment. The type of education was evident in the 1966 Rhodesia Front bottleneck education policy which stated that, out of the total population of African students who completed Grade 7 only $12^{1 / 2}$ percent were eligible to proceed to Academic secondary schools (F1), 371/2 percent would proceed into vocational education (F2) and the remaining 50 percent were left with no provision of any form of planned formal education (Zvobgo in Mandaza 1987). At independence, in 1980, the new government's first task was to break the several educational constraints placed by the capitalist government against the African child, democratizing the educational system. The achievement of the task of democratizing education was first manifested through the implementation of mass education policies which included amongst other policies, free primary education and automatic promotion from primary school level to secondary school. As a result of the mass education policies the then Minister of Education Fay Chung reporting in The Herald of May 1995 stated that:-

Primary education had risen from 1700 to 4500 and the number of Primary school children leapt from 800000 to2.3 million. Secondary Schools saw a similar expansion from 6000 students in 173 schools to 700000 in 15000 schools by 1995 .

This was a successful quantitative expansion in education. However, although the issue of quantity and access had been successfully addressed issues of relevance, quality and effectiveness needed to be addressed too. Hence in 1998 the President of Zimbabwe (as Head of state and government) commissioned DR C.T. Nziramasanga as chairman of other educationists to conduct an inquiry into the Zimbabwe education and training. Quite a number of findings were brought out by the commission but of interest to the research are the findings concerning government secondary schools, of which some are stated below:-

- Internal efficiency is an important dimension of the concept of the success and quality of education (Nziramasanga , 1999:53)

- There was overwhelming evidence to the effect that our secondary education was a waste of time for the majority of our students. That widely held view was prompted by the fact that our education system handles secondary students as if all of them would end up doing A 'Level' and university studies, (Nziramasanga, 1999:307) 
- The commission was informed that the country was still giving to all secondary students, an old British type of education. The respondents pointed out that for most students the current education system resulted in frustration and sense of failure. (Nziramasanga ,1999:307)

- Most parents bemoaned a situation where after four years of secondary education their children left school without practical skills. (Nziramasanga, 1999)

From the findings listed above it becomes evident that the key stakeholders were not happy with the type of education given to their children, hence there was a need to change the secondary school leadership approach if the schools were to remain effective in the turbulent society of the $21^{\text {st }}$ century.

However, it should be noted that the study by the commission was carried at a time when the teachers, who are the backbone of any educational system, were working under trying conditions. The Zimbabwean teachers were faced with low salaries coupled with work overload in terms of professional demands and high teacher pupil ratios. The same teachers felt that they were deprived of their professional freedom too, as they were not involved in the school decision making processes (Nziramasanga 1999). As a result this caused them to have an indifferent attitude about their work. Low morale was, generally, observed in the schools. School leadership, experienced the same difficult conditions too but remained with the task of controlling the demotivated teacher towards achievement of objectives. The Chronicle of 10 June 2009 revealed that one school reported a drop from $83 \%$ to $68 \%$ pass rate at A 'Level' November 2008 results. One school described the pupil performance as 'dismal'. However, it is interesting to note that some schools recorded success even under such difficult conditions. It thus becomes interesting to study the transformational leadership approach under the described conditions as a means of understanding how leadership influence can produce varying results under similar conditions.

The poor economic conditions in the country also led to a limited supply of material resources in the schools creating a challenging environment for both teachers and administrators. In The Chronicle of 25 September 2009, Senator David Coltart, the Minister of Primary and Secondary Education, Sports and Culture made the following observations:-

The Education Sector like many other sectors in Zimbabwe was severely affected by the sanctions imposed on the country by the west. As a result of the embargo the Government failed to pay teachers good salaries and for the greater part of last year no lessons took place.

On the other side communities, particularly urban, have developed notable interest in the education system in Zimbabwe and they have come to realize their role as key stakeholders. Similarly the very pupil who is a client and the processed input has been enlightened about educational expectations through global village influence. Therefore choice of a school is in most cases influenced by what the school administration has to offer more than just mere vicinity of that school. Leadership in this case becomes the key towards fulfilment of key stakeholder expectations in as far as instructional, administrative and curricular tasks about any school are concerned.

Leadership is influence and if well exerted gives an organization a unique character and form, towards achievement of set goals under any given conditions. It is in this light that the concept of transformational leadership was studied in Bulawayo Government Secondary Schools.

\subsubsection{Problem Definition: Key Question}

How can transformational leadership be effectively utilized in Zimbabwean Government Secondary Schools?

\subsubsection{Related Question}

- What is the meaning of transformational leadership to government secondary schools?

- How does transformational leadership differ from transactional leadership as applied to government secondary schools?

- What are the key components of the transformational leadership theory and how do they apply to education?

- How can the transformational leader's view of organizational change influence productivity in Zimbabwean government secondary schools?

- To what extent can motivational factors be linked to transformational leadership in education?

- How relevant is transformational leadership as a structural intervention strategy in government secondary schools in Zimbabwe? 


\subsubsection{Primary Purpose of the Study.}

The primary purpose of the study was to explore the extent to which transformational leadership could increase productivity in Zimbabwean government secondary schools.

\section{Defining leadership.}

The understanding of the concept of leadership has evolved over time. Yet it becomes even much more important to understand its definition in this century of globalization and turbulence. Organizations today exist in turbulent times and leadership for competitive advantage is the expected norm. Thus the understanding of what leadership entails becomes even more critical especially if all organisations have to be effective and efficient in achieving their mandate. Through lack of leadership, organisations have been observed to underperform. Thus the substance not the style gets to be core issue to be addressed in the study of leadership so that an authentic foundation for any organisation that seeks to attain its results is successfully built.

John Gardner in Sadler (2003:5) defines leadership as; 'the process of persuasion or example by which an individual (or a leadership team) induces a group to pursue objectives held by the leader or shared by the leader and his or her followers'. The emphasis in this definition is on the leader who has to induce his/her followers towards attainment of goals. Hence the application of the old Chinese proverb that, 'if anyone thinks they are leading, but has no one following them, they are merely taking a walk'. Gary Yukl in Sadler (2003) states that;

...leadership involves influencing task objectives and strategies, influencing commitment and compliance in task behaviour to achieve these objectives, influencing group maintenance and identification and influencing the culture of an organisation.

Yukl brings another dimension of leadership as influence. To him leadership is complete when there is influence of task objectives, influence of commitment, influence of the group and influence of the culture of the organisation. Those are the four dimensions that have to be influenced if the organisation has to achieve its objectives. It is, however, not clear in this definition how one has to successfully influence his or her followers. Evans (1996:207) defines leadership as 'influence or the art, skill or process of influencing people to work towards the achievement of group or larger organisational goals". Evans brings in 'art and skill' as a control of influence which is also a process. According to him followers have to be motivated to follow the leader. The leader should thus influence, persuade and inspire his followers. The element of art shows that leadership is a highly creative activity (Landsberg, 2000). Successful leaders encourage the creativity and initiative of their followers through effective, supportive or coordinative behaviour. Domination is not a necessary skill of leadership hence Coleman (1996) in Parker and Stone (2003:102) says: "Leadership is not domination but the art of persuading people to work towards a common goal". According to Coleman leaders need to employ a combination of professional, personal and political skills in order to persuade and influence others and should exhibit the ability to create and share the meaningful vision, each time motivating their followers and constantly improving the existing systems so that satisfaction with a prescribed status is achieved. The word 'art' brings in the element of creativity and innovativeness of the leader during the persuasion process. The leader has to be creative and not just ordinary and mundane.

Walter F. Ulmer Jr. brings in an interesting issue of leadership and formal positions and authority. According to Ulmer in Sadler (2003:5) leadership is,

An activity-an influence process in which an individual gains that trust and commitment of others and without reliance on formal position or authority moves the group to the accomplishment of one or more tasks.

One can thus conclude that leadership can be found in any levels of the organisation and one does not need to be in authority to lead but power of one kind or another is needed for one to successfully influence his or her followers to perform their duties productively. Hence Smith and Cronje (1997) argue that power has to be earned. Once earned, this leader gets to be influential.

Perhaps of great importance is also the fact that leadership should be understood as a process. Smith and Cronje (1997:278) say; "Leadership is the process of directing the behaviour of others towards the accomplishment of certain objectives". Defining leadership as a process facilitates the understanding of all group dynamics linked to achievement of objectives. It also facilitates the understanding of all the activities linked with formation of plans and objectives and the necessary steps taken to achieve those objectives. As a result the leadership concept is widely encompassing thus remains an elusive concept for one to define specifically and precisely. Perhaps as a conclusion to this section one might choose to consider Kevin and Freiberg's, (1996) in Marturano and Gosling (2008; 97);

Leadership is a dynamic relationship based on mutual influence and common purpose between leader and collaborators in which both are moved to higher levels of motivation and moral development as they affect real, intended change. 


\subsection{Leadership and management}

It gets to be essential, in the study of leadership, for one to understand the relationship between leadership and management. Perhaps for one to understand that relationship much clearer one has to start by realising the four management functions of planning, organising, controlling and leading. If leading is one of the management functions, it therefore means that management is broader than leadership. John Kotter in Robbins (1993) argues that leadership is different from management but for different reasons. According to Kotter, management is about coping with complexity, dealing with all functions of management including leading, whereas leadership is about coping with change.

Leadership focuses on developing a vision about the future. The leaders focus on the long term, the horizon, take risks, want to do the right things and thus appeal to both emotion and reason, rely on trust, inspire, innovate, urging people to a new vision and uses personal influence. Landsberg (2009). Management on the other hand focuses on the present, seeking to maintain order and to do the right, contains risks through appealing to reason and targeting efficiency. John Kotter thus argues that both strong leadership and strong management are needed in organisations if the organisations have to reach their optimal effectiveness. But he remains with an argument that most organisations fail because they are over managed and under led.

\subsection{School leadership}

Schools can be said to be pure service providers on one hand and producers of products on the other hand. Services are intangible acts whilst products are tangible things that one can handle and drop (Davis et al: 2003). Considering that the school services the community, educating the community's children, the school can be said to be a service provider yet if one considers the fact that pupils come out as an output from the school then schools can be said to be product oriented. The pupil can be a client or customer accessing a service from the school while at the same time the same pupil gets to be the end product. This makes the schools a special type of organisation whose success is measured by both the interaction during the service and by the assessment of the end product. School leadership thus needs to ensure both immediate customer satisfaction and long term reception of the goods/products both as an outcome and as an output.

Whilst the achievement in terms of examination results can be immediate, the well being and school outcome could be measured in the long run. Parents in the long run look back and view the long term benefits from the school through making an analysis of either positive or negative future roles exhibited by the former school's students. It is on this line that parents then demand accountability from the head expecting him/her to manage and lead the whole school community into measurable success. The parents demand to see the head's control over both the teachers and the pupils. This is because the community sees the quality of both the teaching and learning being based on the effect the teacher has on the pupils' learning experiences and the effect the head has on the teachers. As a result, each school gets to be a unique entity whose demands vary according to the community values and the type of the head leading the school.

The school leadership comes in the form of the head of school, the deputy head, teacher in charge, head of department or the teacher in the classroom. Despite the number of persons in the school leadership team, the head of each school remains accountable to the authorities and the community on the day to day running of the school. Hence Copozzoli, (2009:1) defines school transformational leadership as;

....an adaptive process in which school communities work together to build a cohesive understanding and collaborative actions to ensure the attainment of the school's purpose, collective goals, and shared vision through the development and sustainability of a successful learning environment thereby promoting and supporting highly personalized, differentiated, student-centred, self directed, educational learning experiences for all its members.

It is in this regard that transformational leadership in schools will be explored seeing that leadership is an essential quality in any school head. Leaders have to transform their schools into something unique which according to Rehfeld (1994:10) could also be described as the 'alchemy of a leader'. Rehfeld (1994:1) defines the alchemy of a leader as 'the art of transforming something common into something special'. The school head is challenged to transform a common government school into a unique and special school.

\subsection{Transformational leadership and transactional leadership}

In 1973, Downton J.V. did a research study entitled, 'Rebel leadership; Commitment and Charisma in the revolutionary process', and it are in this research that the idea of transformational leadership was first mentioned. [Simic':1998]. Thereafter James MacGregor Burns used the term, transformational leadership in his book; 'Leadership' in 1978. This was followed by a presentation of the transformational leadership theory formally by Barnard M. Bass in 1985 after which in 1986, Noel M. Tichy and Mary Anne Devanna published a book entitled, 'The Transformational Leader'. It was after a series of researches that Burns discovered that what organizations needed was not the traditional predictable style of leadership but a new, context responsive style, 
which he termed transformational leadership. The leaders needed to 'clarify the present, show how the past had influenced the present and propose a view of the future' (Kakabadse and Kakabadse, 1999:5) if they were to remain productive, effective and transformative. Burns (1978) thus defined the transformational leadership process as, 'a process where leaders and followers engage in a mutual process of raising one another to higher levels of morality and motivation.'(SEDL, 2010:4)

In order for transformational leadership to be understood clearly, James MacGregor Burns brought in the concept of transactional leadership and compared the two concepts. Burns viewed transactional leaders as 'managers who kept the organization going in the same direction' (Georgiades and Mcdonnel, 1998: 98). The main emphasis was on interpretation of the existing status quo and control. Hence Kakabadse and Kakabadse (1999:5) describe transactional leadership as involving 'namely the skill and ability required handling the more mundane, operational, day to day transactions of daily life.' The latter transactions are mainly daily focused, common and of a similar pattern each and every day. They concentrate on the maintenance of the status quo through the traditional and banal activities. Measure of creativity is very limited if existing at all, otherwise the whole process is about accuracy and precision of an ordinary plan. Simic (1998:50) hence observes that in transactional leadership, 'the relationship leader-follower is reduced to simple exchange of a certain quantity of work for an adequate price.' Emotional involvement and commitment is limited as employees are there to complete routine tasks assigned to them. The leader simply assigns tasks to the followers and the tasks have to be performed as per instruction or by the book. Employees are treated as objects that perform tasks and the personal aspect of individuals as having depth of experience is ignored. The whole process could be said to be devoid of freshness.

However, the story is different with the transformational leader. Instead of nursing the day to day tasks the transformational leader is expected to go beyond a day and look into the future to see a bigger picture of the organization. The leader sees beyond the current context and seeks to uplift the organization to that envisaged level. All the set rules and policies are interpreted into the context of the organization so that they are always, fresh, relevant and abreast with the demands of the school and the community.

\subsection{Four elements of transformational leadership}

Bass and Avolio in Simic (1998) analysed the transformational leadership skills and categorized them into four elements commonly referred to as the "Four I's". The latter refers to Idealized influence, Inspirational motivation, Intellectual stimulation and Individualized consideration.

Idealized influence is about gaining support of the followers. The leader builds confidence in his or her followers through a number of characteristics like being sincere, being focused, being enthusiastic about the future and being clear of what he or she stands for. This results in followers believing in both the vision and the leader. The leader gets to be taken as a role model and the followers who trust and respect the leader then emulate him or her. This leads to everyone in the organization sharing the same enthusiasm. This is then linked to the other 'I' of inspirational motivation which is about the leader inspiring the employees towards the vision of the organization. This depends on how the leader articulates the vision. The leader has to articulate the vision in a way that is appealing and inspiring to the employees and all stakeholders. It becomes easier if the followers were involved in the crafting of the vision right from the start.

This could be by accommodating followers divergent views and needs hence the other 'I' being identified is individualized consideration. All employees have to be treated as individuals. This can only happen if lines of communication are kept open so that sharing ideas is accomplished. Individual consideration would mean acknowledging and recognition of individual performance. The leader delegates projects in order to create learning experience (Avolio, 1999). Every individual in the organization is a valuable asset as they can generate ideas that could solve encountered problems. It is therefore, necessary that individuals are empowered to think instead of regarding them as empty vessels.

Intellectual stimulation is about innovativeness, creativity and independent learning. This is a continuous process of assessing situations towards creation of new ways of solving problems. Current situations are constantly reviewed and new opportunities explored. This encourages entrepreneurial approach to viewing situations because both the leadership and the employees do not get satisfied with the status quo. There is always that challenge to do better than before.

Perhaps in order to understand transformational leadership one can also make use of the research by Warren Bennis and Burt Nunus [1985] in their book, 'Leaders -the strategies for taking change'. In this research Bennis and Nanus in Georgiades and Mcdonnel [1998] identified four areas of contemporary leadership to be management of attention, management of meaning, management of trust and management of self. The success of the transformational or contemporary leader lies in the management of these areas.

Management of attention is linked to the assumption that followers will follow a leader with a meaningful vision. The leader should draw attention of the followers by creating a 'catchy' vision. The vision 
should be that which draws the attention and the eye of the followers creating a concrete picture in the minds of the followers.

Management of meaning centres on explicit and clear communication of the vision. The leadership has to make sure that everyone understands the meaning of the vision and the organization grows when meanings are shared.

People will follow someone they trust. Management of trust, therefore, gets to be vital in any leadership that brings about change. Bennis and Nanus [1985] in Georgiades and Mcdonnel, (1998) described trust as an 'emotional glue', 'a lubricant', 'a basic ingredient' and as result a measure of the worthiness of leadership. It is a clear and attainable vision that makes the followers have trust on the leadership and it is this trust if attained, which legalizes leadership. Management of self is about the self reflection and continuous learning and improvement of the leader.

Arguments have been raised about whether transformational leadership alone could lead to success. In answer to that Ken Parry in Simic (1998) suggests that the characteristic of managerial ability is needed in transformational leadership. Leadership would not always be change and taking risks but the managerial skills of control, delegating and supervision are needed if the transformational leader would succeed.

\subsection{Transformational Leadership and motivation}

Burns (1978) observed that transformational leadership aims at moving beyond peoples' wants and desires into the real needs and values (Price in Marturano and Golsing, 2008). Transformational leadership raises both the leaders and the followers 'into higher levels of motivation and morality' (Burns, 1978:20). The leader moves the followers from their basic needs into higher order needs where they move beyond self interests into the interests of the organisation. Motivation gets to be a needed end result during the relational process of transformational leadership. Motivation refers to the forces within an individual that account for the level, direction and persistence of work effort. Man by human nature is a wanting animal, ever searching to fulfil needs and wants. Whenever the surface needs are fulfilled man seeks to fulfil the second sets of needs. It is this assumption about human nature that the leader's decisions should be based on because it is these needs that display certain behaviour patterns in man.

These behaviour patterns have been studied and motivational theories propounded by researchers like Maslow (1943), McGregor (1960), Adams (1963) and Hertzberg (1966). All these theories demonstrate man's search for meaning which Frankl (1969) identifies as "the will to meaning". Maslow observed a sequential pattern of needs which he presented in a five layer pyramidal form with the lower order needs of physiological needs, security and love at the broad base and the higher order needs of self esteem and self actualization at the apex. Maslow's theory was in agreement with man's will to meaning as a primary concern which Paulo Freire refers to as rooted in 'men's incompleteness'. It is because of the men's incompleteness that men go searching for a meaning 'seeking to be more fully human' (Freire (1972:64). The transformational leader thus ensures that man is ever engaged in something meaningful and this something meaningful will according to Maslow vary from man to man. Prioritization of needs will vary according to individuals and the leadership. According to Bass (1985) and Burns (1978)

'Leaders help their followers to reach a higher level of moral responsibility and appeal to them to participate in the process of generating and maintaining a shared vision and to commit to the resulting organisation. [Marturano and Gosling [2008:113].

A sense of belonging is created through search for meaning engaged on valuable experiences with members of the organisation through the guidance of a leader. McGregor, in his theory viewed the organisation from the leaders' point of view. To him, organisations were built upon the continuum of beliefs managers had about their employees. The managerial decisions made, were controlled by the assumptions managers had about their employees. McGregor came up with theory X which was based on negative assumptions and theory $\mathrm{Y}$ which was positive. According to theory X, workers had a general dislike for work and avoided responsibility whilst in theory Y the assumption was that people enjoyed their work, exercised commitment and self control, sought responsibility and enjoyed decision making. (Marturano and Gosling: 2008). According to McGregor, employees would exhibit the theory $\mathrm{X}$ assumptions because of the management methods used. If employees were not performing it was due to bad methods used by managers, hence transformational leadership's appeal for trust in the employees because they were naturally willing to work.

Stacy J. Adams [Marturano and Gosling, 2008] observes that the view by the employee had great impact on satisfaction and performance. Once the employee attached great value to the reward as to see it equitable with the expended effort then a positive result of job satisfaction occurred but if less value was placed on the reward then feelings of dissatisfaction ad reduced performance are the end result. Transformational leadership understands that effective employee performance is not about the types of rewards but about how the employees view those rewards. Whenever tangible rewards were given, it became the leader's responsibility to study the perceptions of employees about these rewards so as to award and minimise negative perceptions that 
will lead to dissatisfaction and low performance. Having realised that humans have needs which they forever wish to satisfy it is therefore important for management to identify these needs together with the established patterns for fulfilling them. A deep understanding of these patterns would assist leadership succeed in influencing the followers through successful translation of these needs into meaningful goals so that the primary motive of man's search for meaning is fulfilled.

Hence Kotter (1990) in Kennedy (2008) views leadership as having a task of appealing the very basic and untapped human needs of values and emotions (Kennedy, 2008; 167) which Daniel Yankeovich in Senge (1990:5) refers to as 'the intrinsic benefits of work' and goes on to say;

The ferment in management will continue until we build organisations that are more consistent with man's higher aspirations beyond food, shelter and belonging.

\subsection{Transformational Leadership and organisational change}

The transformational leader draws employees together through a vision that takes the whole organisation into the future. The task of leadership therefore is to direct and incite employees towards perceived opportunities in a way that would raise confidence and enthusiasm in the followers. This process has to be continuous otherwise organisations remain stagnant and comfortable in stability and equilibration. Change in the organisation is thus introduced in this way to an extent that Gosling in Marturano and Gosling (2008) observes that leadership is at times defined as "creating change". Kotter (1990) in Kennedy (2007) also observes that "leadership produces change" and that was the primary function of leadership.

Change can be defined as an alteration of the status quo, an adaptation of a mode or a shift of perception. This is facilitated through the influence the leader has on employees. Hence Kotter (1990) in Kennedy (2008) identifies the principal tasks of leadership in pursuance for change as the following:

- Establishing direction, developing a vision and strategies for the future of the business

- Aligning people- getting others to understand, accept and line up in the chosen direction

- Motivating and inspiring people by appealing to very basic but often untapped human needs, values and emotions (Kennedy, 2007:167).

Owen (1987) views change as embedded in individual's self awareness that comes by through reflection and priority setting in one's life. Change comes from one's 'self mastery' which transformational leaders have to appeal to. This is supported by Freire's(1972:12) conviction that all man;

No matter how 'ignorant' or submerged in the 'culture of silence' he may be is capable of looking critically at his world in a dialogical encounter with others. Provided with the proper tools for such an encounter, he can gradually perceive his personal and social reality as well as the contradictions in it, become conscious of his own perception of that reality and deal critically with it.

Leadership would assist man to realise his/her deeper self. Through the leader's inspiration, new hope is stirred and new sense of dignity gained. It is this self awareness in individuals that would later cascade to everyone in the organisation thereby resulting in organisational change.

Today's organisations have been viewed as learning organisations because of the fact that they have to continuously adapt to the ever changing environment if they are to survive. Peter Senge concludes that successful organisations of the century would be those organisations that learn faster than their competitors. The 'learning' is not with the leader but according to Senge all man, deep down was a learner. Man was by nature intrinsically inquisitive and therefore, leadership had a role to play in directing that natural willingness to learn so that pro-active change occurs in both the individual and the organisation. Organisations, according to Senge (1999) were products of how people thought, making it vital to give people the opportunity to change how they think if one wanted to change the organisation.

The transformational leader's role was to make use of that deeper hunger for learning in individuals as a way of changing both the individuals and the organisation. It is hoped that a meaningful change in individuals would lead to a meaningful change in the organisation. Senge goes on to note that the type of learning should not only be adaptive, but generative as well, if it had to last.

The change process is cyclic, continuous and ever changing focus to suit the demands of the individuals, the leadership and the organisation. The leader is seen as a researcher and designer because as a leader one has to be aware of both the internal and external forces driving change.

\subsection{Transformational leadership and organisation structure.}

Transformational leadership survives on effective communication channels and as such it is vital that the structure of organisations have to be those that promote transparency and meaningfulness in communication. Noel Tichy and Mary Anne Devanna (1986) in Kennedy (2007:43) observed that; 
Once transformational leaders create a vision and use it to mobilize individuals in the organisation, they must turn their attention to designing new organisational structures and processes so that vision can be achieved.

It is not enough to merely craft a vision but further on the leader has to design a structure that would promote the implementation of a vision. Tichy and Devanna refer to the structure as 'social architecture' as it involves members of the organisation interacting to fulfil the organisational vision. The leader according to Burns has to design the means to the end. How best can the organisation achieve the goal? Which is the best structure that can be used? In other words it is not about designing the end but it is also about how the organisation gets to the end. The creativity of the transformational leader will, therefore, be observed as he/she shapes and re-shapes the structures in the organisation "to achieve broad human purposes and moral aspirations". (Kennedy, 2007:43).

These structures should promote effective communication and be in line with the authority concepts of the organisation. To be observed could be the fact that too much authority leads to authoritarianism which encourages submission and frustrated aggression. Yet transformational leaders seek to emphasise on team work and participatory approach. On the other hand little authority "will provide no strength or solidarity against which to react (Lasch, 1977, 1979 in Marturano and Gosling, 2007:10). It is, therefore, vital to come up with an authority structure that would promote the elements of transformational leaders as exhibited in the four 'i's of idealized influence, inspirational motivation, intellectual stimulation and individualized consideration (Bass and Avolio).

Senge, however, sees this element of structure settled in his fifth discipline of systems thinking. The organisation has to be viewed through its interrelationships rather than as existing in linear pattern. The linear cause and effect chains would result in one way communication and limited feedback. Actions have to be seen to counterbalance and reinforce each other and this can only occur where the structures are viewed in interrelationships and interconnections. Hence Senge in Kennedy (2007; 267) observes that;

If people do not share a common vision and do not share common mental models about the business reality within which they operate, empowering people will only increase organisational stress and burden of management to maintain coherence and direction.

It is, therefore, not about the type of structure but about the interrelatedness of the various levels and systems.

\subsection{Leadership and organisational culture.}

The day to day running of an organisation is regulated by the organisations culture. It could be the decision making the organisation cognitive aspect, the perceptions and attitudes are regulated by the organisations culture. There is a notable link between the organisational strategy, culture and structure. Culture can be defined as a pattern of beliefs and expectations shared by the organisation's members. Schwartz and Davis (1981) in Kennedy (2007). The culture of the organisation thus cuts across the organisation's decision making processes, the objectives, competitive advantage, management systems and the information systems.

When making decisions or in crafting the vision, the transformational leader will be guided by the general beliefs of the organisation and furthermore on crafting the means the form of culture prevalent in the organisation will regulate the means. Charles Handy observed that the forms of culture could be either club culture, role culture, task culture or person culture. If the organisation's emphasis is on the central core then the strategy as means will show club culture and an organisation emphasising on role culture will show emphasis on defined jobs, rules and procedures. Hence Geert Hofstede in his study of culture defined it as "the collective programming of the mind which distinguishes members of one group or category of people from another" Kennedy, 2007:116.) These patterns of thinking are usually crystallized in institutions and hence passed on from one generation to the next. These patterns also get to be crystallized in the society and hence influence governance of organisations in that society. The four patterns which Hofstede identified to be governing cultures were; uncertainty avoidance, power distance, masculinity-femininity and individualism- collectivism. A transformational leader in any situation will seek to study the influencing pattern of culture before coming up with the strategy and the means of achieving that strategy.

\subsection{Challenges in transformational leadership}

Transformational leadership like all the leadership approaches has its own challenges. Because of its emphasis in ever moving forward to meet the current needs of the group, the major challenge would be resistance to change. People resist change when they are comfortable with the status quo. The transformational leader might also be faced with an overpowering organizational culture where the followers highly value their norms and values even if those norms have ceased to be productive. Appealing to the people's belief system could be a challenging task. Instead of the leader changing the organization, people might see it fit that the leader has to change to suit their organization.

Transformational leadership strives on availability of both material and human resources. A supporting community is therefore needed so that the needed resources are supplied. However, even without the adequate 
resources, a transformational leader can use creativity to improvise and prosper. The human resources are not only about the numbers but also about academic empowerment and independent thinking. Teachers have to be confident enough to make constructive decisions. Low morale could, however, be a hindering factor, especially where employees feel that the effort expended at work does not match the rewards gained.

Transformational leadership succeeds better with a stable workforce. High staff turnover interferes with the continuity of programmes hence low production.

\section{Research Methodology}

The research study used qualitative research methodology. In order to analyse and study themes in detail, phenomenological research paradigm of qualitative research methodology was used. The paradigm was suitable for this research as it studies human experience in its own natural existence. The occurrences in the school leadership were described from their own setting and context. As a result direct experiences were described and the existing reality socially constructed. (Leedy, 1997; Thomas and Nelson, 2001; Mouton, 2004).

A case study method was used in this research. The sample was a total of 215 teachers drawn from a total of 762 teachers in government secondary schools of Bulawayo. Because the study involved multiple variables, multiple sources of information were therefore used. A variety of data collection procedures were used thereby giving the 'greater validity' (Burns and Grove, 2001; 545). Use of a variety of data collection techniques facilitated data triangulation. Both qualitative and quantitative data were collected in this study through the use of document analysis, observation, interviews and questionnaires. Documents formed an important source of data. The sources of data in this research were mainly examinations and achievement records, government publications, official statistics, circulars and memos.

Systematic observation was also used in this research and questionnaires were the main instruments used to gather factual data from the respondents. (Tuckman, 1978, Haralambos and Holborn, 1990)

To further solicit information from the respondents, one-to-one interview with key informants was conducted. This is a study of the transformation leadership approach in secondary schools and it was hoped that all the intricate variables leading to the approach's effectiveness would be identified.

\section{Research Findings}

\subsection{Selection of School Heads}

The interviews of District Education officers, Deputy Provincial Directors and the Provincial director plus an analysis of selection documents revealed that all heads of schools in the Bulawayo district were first degree holders and in some cases holders of a Masters Degree. An administrative degree was enough for O' level secondary school but a first degree in any of the subjects offered in the secondary school curriculum was a prerequisite for A'Level secondary schools. All heads had a teacher qualification from a recognized university either as a Diploma/ Certificate in Education or as a Post Graduate diploma/certificate in education. Graduate holders without teacher qualification were not considered during any selection process for headship. The selection was done on free competition basis with three applicants short listed per post. A first degree was thus a pre- requisite and the applicants were to have no misconduct charge. Performance approval forms were used in the selection process and all applicants were to have a score that was above a 3 .

During the selection interviews, the interviewees revealed that it was the applicant who displayed full knowledge of the job who got the post. The applicant would display professional knowledge as he/she would have been a deputy head before, giving the applicant the needed professional experience and the knowledge of school administration. The interviews revealed that the key qualities that the applicants were expected to display during their interviews were; initiative, intelligence, maturity, creativity, innovativeness, communicator, articulacy, assertiveness and firmness amongst many others. Whilst some key informants felt that rural experience was an essential experience, others were of the view that the applicant could actually fit the urban situation after graduation from being a deputy head in the urban school. These were the informants who felt that a leader needed to grow and mature in a certain environment over time if he/she had to perform well. One can thus conclude that heads of the Bulawayo Government secondary schools had higher academic qualifications and in most cases, higher than the average people in their society. They were, therefore, expected to be intelligent (Lulee, 2011) especially considering that they were leading a group of educators.

Placed in any of the schools in the city, the head was therefore expected to excel, especially after going through the competitive selection process. The provincial office revealed that the appointed head was expected to produce good results, to have good public relations with the community, and ever remain bold and focused. Whilst all schools were governed by national government policy, the implementation of the policy revealed the innovativeness of the head. The Provincial Director reiterated the fact that policy merely gave guidelines but the "how" depended on the head. He added that, "policy was not meant to kill individual flair." Policy merely provided framework within which the school would operate under the leadership of the head as the driver. 
As revealed earlier on this study the secondary school curriculum in Zimbabwe offered about 38 subjects at $\mathrm{O}$ level. The selection of the subjects, of course guided by the Policy circular No P77 0f 2006 for Two pathway Education structure in Zimbabwe would show the heads initiative as he/she explained both the local and national environment in terms of relevance and future use. All the policy provided was a framework of operation but the selection would depend on the head s understanding of the expectations of the surrounding tertiary institutions and the industry at large from the interviews carried out. Therefore, it was revealed that after the meticulous selection, the head was not placed in the school just to maintain and nurse policy but to create a unique school under the framework of the given policies.

\subsection{General performance of Heads}

Since the framework of collecting data was based on Bass and Avolio's four '1' of transformational leadership, data presentation, analysis and interpretation will also be presented under these categories. In the interpretation the categories will be linked with Bennis and Nanus' [1985] in Georgiades and Mcdonel[1998] four areas of transformational and contemporary leadership and Leithwoods six factors of transformational leadership. From these three sets of elements, the emerging attributes formed the basis of analysis of transformational leadership in education.

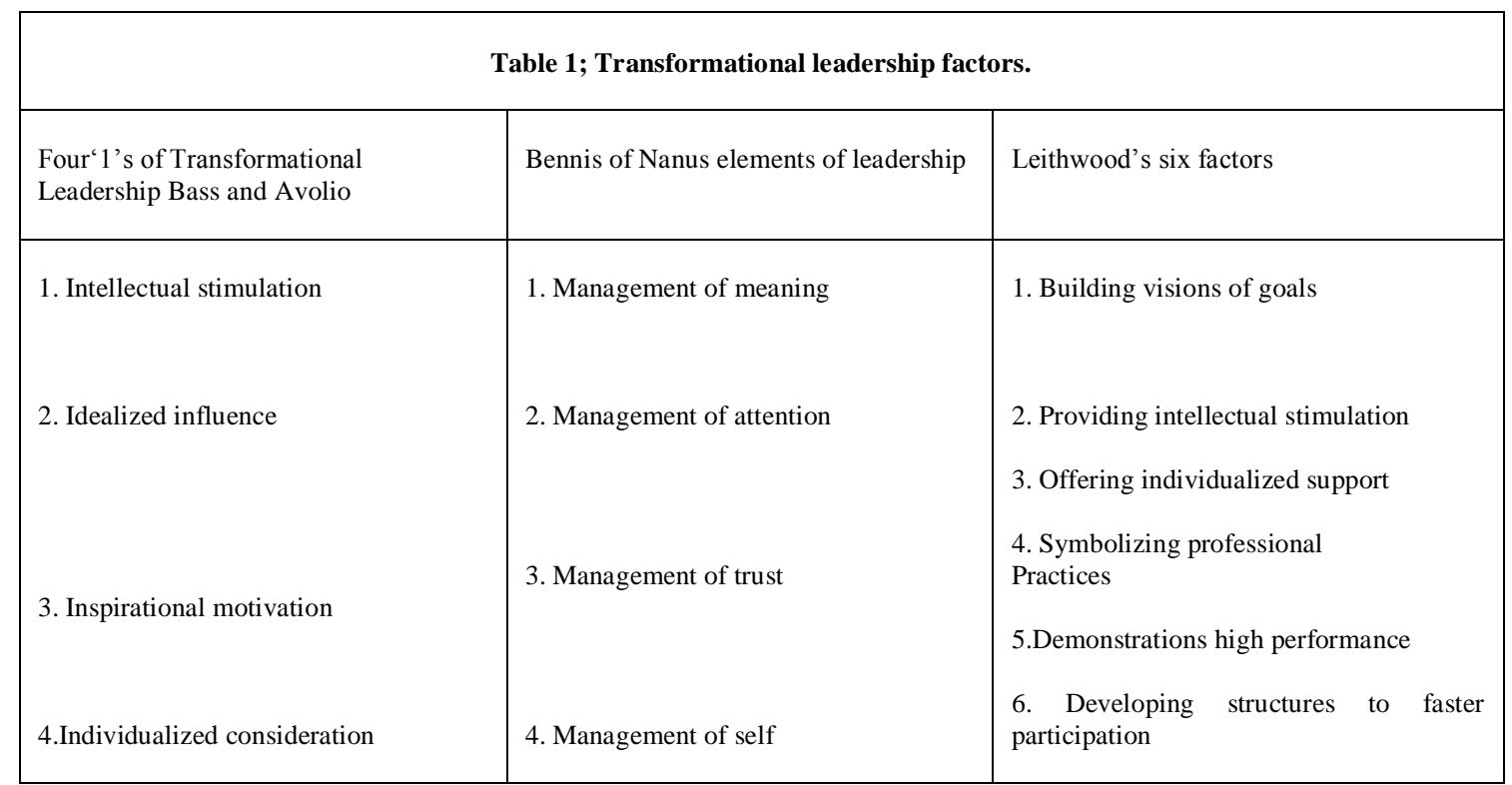

Below are some of the emerging attributes of transformational leaders drawn from the three sets of elements and factors identified above;

Table 2; Transformational leadership attributes.

Problem solver, Confident, Compelling, Sincere/authentic, Role model, Tactful, Holds a bigger picture, Courageous, Confident, Compelling, Sincere/authentic, Role model, Tactful, Holds a bigger picture, Independent thinker, Explorer of opportunities, Clear and effective communicator, Social architecture, Creative, Commitment to both vision and organization, Emphasis on life-long learning and personal empowerment, Emphasis on teamwork, Trustworthy, Visionary, Able to inspire followers, Full of integrity, Reflective, Emphasis on diversity of ideas, Monitoring and recognition of individual performance, Emphasis on growth and self, Sensitive to the needs of others, Acknowledgement of success, Delegator, Enthusiastic, Positive.

It is against these attributes that transformational leadership was explored in education with the hope of finding out the extent secondary education is from establishing leaders with remarkable capabilities, leaders who see beyond policy, leaders who create lasting opportunities out of simple government policies.

The key used in the analysis was

$1 \quad$ - $\quad$ Skills gap and possible weakness

2 - $\quad$ Sometimes competent but inconsistent

3 - $\quad$ Usually competent and effective

$4 \quad$ - $\quad$ Always competent and at times exceptional

$5 \quad$ - $\quad$ Star performer and inspirational to colleagues 
In the analysis of the heads, the scores 1, 2, 3 were grouped together as heads not displaying the remarkable capabilities warranting one to be identified as a transformational leader and 1 and 2 taken to be the star performers.

- One of the major concerns of the study was to observe and bring out how school leader reacted to change. The leader needs to understand the context within which the organization operates and particularly taking note of the strengths and weaknesses of that particular school. It, therefore, requires that the leader should be positive and enthusiastic about the work challenges around him/her and be an action person all the times. $11.6 \%$ of the teachers felt that leaders had a skills gap in being enthusiastic about their work challenges, $17,2 \%$ stated that their leaders were at times competent but inconsistent and $34 \%$ stated that their leader were usually competent. This gives total $62.8 \%$ leaving $37.2 \%$ to be on the exceptional side. This, therefore meant that, generally, school leaders in Bulawayo were not highly enthusiastic about their work challenges. Yet enthusiasm is a key factor in inspirational motivation [Avolio, 1999]. It is an enthusiastic leader who would in turn motivate the followers towards the given work challenges.

- One key informant revealed that a leader should have hands that were prepared to get dirty. This was to express the view that organizational development would not come by through theory and ideas but through action as well. It was observed that all schools displayed their vision, mission and core values at their reception areas. Whilst these could be innovative and well crafted, the transformational leader would go beyond this and turn all the ideas into action.

- The principal tasks of a transformational leader are to convince stakeholders on the benefits of change. People will not change if the leader has not convinced them and helped them to embrace change. The two skills are therefore, important if the leader has to assist the school to move in the ever changing times. 13\% that their leaders were weak in convincing stakeholders, $25.1 \%$ were sometimes competent and $34.4 \%$ usually competent (72.5). The stakeholders that need to be convinced and helped to embrace change are the educated staff members (Lulee 2011), the school pupils ,Reynolds in Reynolds and Cuttance( 1982 ) and the community. $24.4 \%$ of the heads were said to be successful in that area yet focus groups revealed community support and involvement as the key to school success. Schools that had worked well with School Development Committees have achieved great heights and those that have failed are always in the paper for the wrong reasons like failing to distribute incentives or buying school trucks without consultations. These would be the symptoms of heads' failure to convince stakeholders so that they buy his/her idea.

- Followers will follow a leader whom they trust and that calls for sincerity honest and authenticity. Bennis and Nanus[1985]in Georgiades and Mcdonnel [1998] did reveal that trust was emotional glue needed by the organization to grow together and it becomes vital for the school leader to display the honesty so that trust is gained. $15.3 \%$ noted that their leaders had skills gap in giving honest answers, 26\% stated that their leaders were sometimes competent and $21.9 \%$ believed that their leaders were usually competent (63.2). $36.7 \%$ of the teachers believed that their leaders were star performers in the element of trust.

Honesty could also be an observed behavior through one accepting responsibility for mistakes. The leader is therefore not always pointing fingers but gives an honest assessment of self. A high percentage of $23.7 \%$ were noted to be failing to accept their own mistakes $20.9 \%$ were sometimes competent and $27.9 \%$ usually competent $(72.5 \%)$ only $27.5 \%$ were exceptional in accepting responsibility for mistakes.

- Collaborative action is the key to transformational leadership. All stakeholders have to be involved. In the school set up teachers, parents and students have to be involved, hence Senge (2002) identifies systems approach as The Fifth Discipline. $8.8 \%$ were said to have a skills gap on facilitating team meetings. $20.5 \%$ were sometimes competent and $30.7 \%$ usually competent. $40 \%$ were on the star performer's category. $7.9 \%$ had a skills gap in brain storming, 27.0\% sometimes competent and 30.2 usually competent (65.2\%). 34.9\% were the exceptional performers. When asked what they would change, a number of teachers indicated that the teacher's views needed to be heard too. Team work had to be encouraged avoiding situations where only the influential were heard. This would come with being assigned tasks and given clear expectations for those assignments.

- Bennis and Nanus emphasize management of attention as essential in visionary leadership. A visionary is expected to have a positive outlook, adapt quickly to new situations and be smarter in doing things. $11.2 \%$ of the leaders were noted to have a skills gap in maintaining a positive outlook, $14.5 \%$ sometimes competent and $31.8 \%$ usually competent (57.5). $42.5 \%$ were exceptional in maintaining a positive outlook. This was quite encouraging especially in the prevailing Zimbabwean situation where the economy has not been so supportive.

- Enthusiasm drives the transformational leader forward towards achievement of goals. The enthusiasm has to be authentic and sincere so that trust is gained from followers. A mere sense of humour might make the leader remain focused under pressure and as an end result create a climate where work is enjoyable. Surprisingly, $24.8 \%$ of leaders were observed to be having a skills gap in keeping a sense of humour. 19.6 were sometimes competent and 21.5 usually competent (65.9). Lack on sense of humour could be due to the 
emphasis on mundane transactional activities where control is emphasized instead of enthusiastic research and designing. It could be worth noting that $63.7 \%$ of the teachers said that they were enthusiastic about what the school needed to achieve. $26.5 \%$ were neutral and $9.3 \%$ were not enthusiastic. Leadership has to make use of the enthusiastic teachers to maintain the enthusiasm even under pressure.

- Pressure should not derail the leader from the organizational focus. It was the transformational leader who emerged focused after the 2007 - 2008 economic melt-down in Zimbabwe. Most schools in Bulawayo had their results plunging to as low as $3 \%$ yet some schools remained afloat. $14.0 \%$ of the leaders were observed to be having possible weakness in staying focused under pressure and that was a high percentage for leaders to have a skills gap in that area. Hence Baulding in Georgiades and Mcdonnel (1998:75) observed that "the greatest need of leadership is in the dark" so that followers are directed towards a new world being born.

- $23.4 \%$ of the leaders were also viewed to be having a skills gap in creating a climate where work was enjoyable. This could be the reason why some teachers described their relationship with leaders to be "nonexistent", master -servant", purely authentic, distant" strained and 'poor'. It is these teachers who indicated that what they would change in the organizations would be the leadership. However, it is interesting to note that on the other side $32.8 \%$ of the heads were recorded to be exceptional performers in creating a climate where work was enjoyable. Interviews revealed that a successful school leader is one who had a quick smile and always ready to give direction and motivation.

- $18.1 \%$ of the heads were said to be having a possible weaknesses in showing that they understood other people's point of view, $21.4 \%$ were sometimes competent and $23.7 \%$ usually competent (63.2\%). In support of the above perceptions, only $43.3 \%$ of teachers felt that their opinions mattered in the organization, $32.1 \%$ were neutral and $24.7 \%$ gave an emphatic "no".

- Understanding the diversity views of followers is important in transformational leadership so as to create a sense of belonging in the followers.

The transformational leader should have 'big ears' to listen well. This listening well should also occur even when in disagreement. Surprisingly a high percentage of $20.0 \%$ of the heads were recorded to have weakness in that listening skill during disagreement. $22.3 \%$ was at times competent and $31.2 \%$ usually competent $(73.5 \%)$ giving a high percentage.

- The heads on the other hand revealed that they could not influence people to address their needs because the needs were money related. However, it was surprising that when teachers were asked about what they would change in organizations a very insignificant number of teachers cited remuneration. This shows that there are much greater needs to be addressed than remuneration if teachers have to perform well. These could also be analyzed through the things that teachers said they liked about their jobs. About $80 \%$ of the teachers revealed that they enjoyed interacting with the pupils and seeing them improve, graduate and become worthwhile citizens. Other issues identified included freedom of creativity and innovation, continual sharpening of one's mind, free and fair environment, making decisions, the unstressful nature of the job, the working hours and the long holidays. Beyond remuneration, the teacher's needs could be derived from these activities and infringing with these items above would produce a de-motivated teacher.

- An organization is able to sustain itself only through shared goals, values and missions. It is the sharing of visions that binds people together in a common identity. The sharing of the goals, visions and values starts with a dialogue [Senge, 1990, Freire, 1972]. Meaning is negotiated effectively through team dialogue. Focus group discussions revealed all stake holders needed to be involved in the decision making working effectively as peers. $12.6 \%$ of the leaders were noted to have a skills gap in working effectively with peers, 19.1 were sometimes competent and 33.0 usually competent [64.7]. 13.6\% had a skills gap in negotiating effectively, $21.5 \%$ sometimes competent and $28.5 \%$ usually competent [63.6\%]. Through dialogue, transformational leadership ensures that ideas are not merely deposited on individuals and also make sure that some do make views on behalf of others (Freire, 1972). It is thus of concern to note that $63.6 \%$ and $64.7 \%$ of the leadership need to be staff developed on negotiating with peers and on negotiating effectively.

- The open ended questions revealed a variety of relationships between teachers and their heads. The descriptions ranged from excellent to nonexistent. Some of the words used to describe the relationship of teachers and heads were; good, warm and satisfactory, can be improved, professional, cordial, formal, smooth, neutral, and sour, and strained, sometimes bad and nonexistent. The transformational leader will seek to maintain positive relationship even during difficult situations.

- Review of related literature by Latchem and Hanna (2001) in Lulee (2011:1) revealed that "educational leaders should see themselves as educators who are capable of enabling other team members to acquire and exercise leadership skills". Leaders have to be groomed in all sectors of the school system from the pupils to the support staff. Reynolds in Reynolds and Cuttance [1982] observes that if pupils could also be included in the authority of the school it would create senior pupils who were generally supportive of the school. Focus group discussions debated on the issue, with some fearing the element of abuse of such an arrangement by 
the pupils and others saying that with strict control a sense of belonging built among pupils could be passed over generations.

- $24.8 \%$ of the teachers revealed that they had received some form of recognition in last four months. $19.2 \%$ were neutral and a good $55.6 \%$ had not received any form of recognition.

\section{Conclusions and Recommendations}

On the basis of literature review and empirical evidence, it can be argued that a head placed in any school has to produce a unique product. Policy was there to guide the leader and not restrict him/her from creating fruitful visions hence the need for transformational leaders in education.

One of the core elements of transformational leadership is intellectual stimulation, yet from empirical research it could be argued that school heads were not highly enthusiastic about their work challenges. Because of this it could be difficult to appeal to the teachers' higher levels of morality and motivation.

Success in transformational leadership is about selling one's vision. There was a notable observation that heads of schools had a skills gap in convincing stakeholders and in helping their members to embrace change. An accomplishment of this skill would lead to the schools being able to quickly adapt to new situations.

Continuous improvement is about reflection and open mindedness. Literature and empirical research showed that heads of schools were highly educated and leading educated personnel. Because of that, heads could profitably make use of the divergent skills possessed by all members. However, research, showed that teachers felt that their opinions and skills were not effectively utilized by their heads. Individualized consideration in terms of recognition and involvement should be practiced in schools if schools are to yield better performance.

The focus group discussions revealed that transformational leadership was needed in education as an answer to the dynamic and turbulent environment. The discussions revealed that with the ever changing times it was the flexible transformational leadership who would be able to identify strategies that would take advantage of the changing environment; the strategies that would go in line with the globalization trends. The respondents thus believed that heads of schools could use transformational leadership to create competitive advantage and uniqueness of schools yet the issue of how policy could be successfully woven into heads' plans remained debatable.

Whilst the respondents endorsed the need for transformational leadership in education, they did, however indicate some challenges that a transformational leader might encounter in his or her practice. These included the head's position in his/her career cycle, the head's personal commitment and the empowerment levels of the teachers, the community and the pupils.

The study recommended that schools as business organizations needed leaders who clearly understood their role in the school production process. Heads of schools should from the initial position work with all stake holders so that everyone willingly enrolled in the shared vision. This included pupils too. A non-linear, but multidirectional and systems approach as means of communication should, therefore, be used to facilitate team work and schools' rapid response to change. Change or redefinition of a school vision should be continuous and should be championed by the head otherwise the school remained stagnant, comfortable with the existing status quo and as a result became irrelevant to both the needs of the society, the pupils and its employees.

Finally, considering the quality qualification of secondary school heads, it would be interesting to see them display their unique leadership skills and become education alchemist so that they all create something unique and special from ordinary government schools. Transformational leadership was thus recommended as a form of leadership to improve results in Zimbabwean government schools.

\section{APPENDICES}

\begin{tabular}{|l|l|l|l|l|l|l|l|l|l|l|l|l|l|}
\hline \multicolumn{7}{|c|}{ Table 3 Teachers' perceptions on the extent to which school heads exhibit transformational leadership factors. } \\
\hline Statement & & $\mathbf{1}$ & & $\mathbf{2}$ & & $\mathbf{3}$ & & $\mathbf{4}$ & & $\mathbf{5}$ & & Total \\
\hline & $\mathbf{f}$ & $\mathbf{6}$ & $\mathbf{F}$ & $\mathbf{\%}$ & $\mathbf{f}$ & $\mathbf{\%}$ & $\mathbf{f}$ & $\mathbf{\%}$ & $\mathbf{f}$ & $\mathbf{\%}$ & $\mathbf{f}$ & $\mathbf{\%}$ \\
\hline $\begin{array}{l}\text { Being enthusiastic about new } \\
\text { work challenges }\end{array}$ & 25 & 11.0 .6 & 37 & 17.2 & 73 & 34 & 50 & 23.3 & 30 & 14 & 215 & 100 \\
\hline $\begin{array}{l}\text { Convincing stakeholders/selling } \\
\text { benefits }\end{array}$ & 28 & 13.0 & 54 & 25.1 & 74 & 34.4 & 40 & 18.6 & 19 & 8.8 & 215 & 100 \\
\hline $\begin{array}{l}\text { Giving honest answers to tough } \\
\text { questions }\end{array}$ & 33 & 15.3 & 56 & 26.0 & 47 & 21.9 & 42 & 19.5 & 37 & 17.2 & 215 & 100 \\
\hline $\begin{array}{l}\text { Helping people to embrace } \\
\text { change }\end{array}$ & 28 & 13.0 & 52 & 24.2 & 64 & 29.8 & 48 & 22.3 & 23 & 10.7 & 215 & 100 \\
\hline $\begin{array}{l}\text { Accepting responsibility for } \\
\text { mistakes. }\end{array}$ & 51 & 23.7 & 45 & 20.9 & 60 & 27.9 & 41 & 19.1 & 18 & 8.4 & 215 & 100 \\
\hline
\end{tabular}




\begin{tabular}{|c|c|c|c|c|c|c|c|c|c|c|c|c|}
\hline $\begin{array}{l}\text { Brainstorming solutions to } \\
\text { problems }\end{array}$ & 17 & 7.9 & 58 & 27.0 & 65 & 30.2 & 53 & 24.7 & 22 & 10.2 & 215 & 100 \\
\hline Maintaining positive outlook. & 24 & 11.2 & 31 & 14.5 & 68 & 31.8 & 58 & 27.1 & 33 & 15.4 & 214 & 100 \\
\hline $\begin{array}{l}\text { Keeping sense of humour under } \\
\text { difficult situations. }\end{array}$ & 53 & 24.8 & 42 & 19.6 & 46 & 21.5 & 36 & 16.8 & 37 & 17.3 & 214 & 100 \\
\hline Staying focused under pressure & 30 & 14.0 & 50 & 23.4 & 54 & 25.2 & 53 & 24.8 & 27 & 12.6 & 214 & 100 \\
\hline $\begin{array}{l}\text { Understanding other people's } \\
\text { point of view }\end{array}$ & 39 & 18.1 & 46 & 21.4 & 51 & 23.7 & 58 & 27.0 & 21 & 9.8 & 215 & 100 \\
\hline Working effectively with peers & 27 & 12.6 & 41 & 19.1 & 71 & 33.0 & 52 & 24.2 & 24 & 11.2 & 215 & 100 \\
\hline $\begin{array}{l}\text { Creating a climate where work is } \\
\text { enjoyable. }\end{array}$ & 50 & 23.4 & 49 & 22.9 & 45 & 21.0 & 35 & 16.4 & 35 & 16.4 & 214 & 100 \\
\hline $\begin{array}{l}\text { Listening to others when in } \\
\text { disagreement }\end{array}$ & 43 & 20.0 & 48 & 22.3 & 67 & 31.2 & 38 & 17.7 & 19 & 8.8 & 215 & 100 \\
\hline Negotiating effectively & 29 & 13.6 & 46 & 21.5 & 61 & 28.5 & 54 & 25.2 & 24 & 11.2 & 214 & 100 \\
\hline
\end{tabular}

\begin{tabular}{|c|c|c|c|c|c|c|c|c|}
\hline Statement & Yes(f) & $\%$ & Neutral(f) & $\%$ & No(f) & $\%$ & $\begin{array}{l}\text { Total } \\
\text { (f) }\end{array}$ & $\%$ \\
\hline $\begin{array}{l}\text { Have you received any form of } \\
\text { recognition in the last four } \\
\text { months? }\end{array}$ & 53 & 24.8 & 41 & 19.2 & 119 & 55.6 & 214 & 100 \\
\hline \multirow{3}{*}{$\begin{array}{l}\text { Do you think enthusiastically } \\
\text { about what the school needs to } \\
\text { achieve? }\end{array}$} & 137 & 63.7 & 57 & 26.5 & 20 & 9.3 & 215 & 100 \\
\hline & & Head & & Teacher & & All staff members & & \\
\hline & $\mathrm{f}$ & $\%$ & $\mathrm{f}$ & $\%$ & $\mathrm{f}$ & $\%$ & $\mathrm{f}$ & $\%$ \\
\hline $\begin{array}{l}\text { Who sets the objectives of the } \\
\text { school? }\end{array}$ & 121 & 56.5 & 25 & 11.7 & 68 & 31.8 & 215 & 100 \\
\hline
\end{tabular}

\section{References}

[1]. Avolio, B.J. [1999] Full Leadership Development: Building the vital forces in Organisation, L.A: Thousand Oaks.

[2]. Bennet, N., Glatter, R and Levacic, R. (1994) Improving Educational Management through Research and Consultancy. London :Chopman

[3]. Borg, W.R. and Gall, M.D. (1993) Educational Research, New York: Longman

[4]. Burke, R.J. and Cooper, C.L. (2004) Leading in Turbulent Times. Managing in the New World of work, Australia: Blackwell Publishing.

[5]. Burns, V, and Grove, S.K (2001) The Practice of Nursing Research, Conduct, Critique and utilization, U.S.A: Elsevier Saunders.

[6]. Chikoko, V. and Mhloyi, G. (1995) Introduction to Educational Research Methods, Harare: ZOU.

[7]. Copozzoli, C. (2009) Transformational leadership- JHU

[8]. Retrieved 02/06/2011 from http://web20-guru.blogspot.com/2009/07/transformationalleadership

[9]. Davis, M.M, Aquilano, N.J. and Chase, R.B. (2003) Fundamentals of Operations Management. M.C. Grawhill: Irwin.

[10]. Evans, D. (1996) Supervisory Management Principles and Practice, UK: Redwood Books

[11]. Freire, P. [1972] Pedagogy of the Oppressed, New Zealand: Penguin Books.

[12]. Georgiades, N. and Mcdonnel, R. (1998) Leadership for Competitive Advantage, New York: John Willey and Sons.

[13]. Goleman, D. (2003) The New leaders transforming the Art of leadership into the Science of result, Great Britain: Clays Ltd.

[14]. Hay, I [2011] Transformational Leadership Characteristics and criticism. Retrieved from http;www.leadingtoday.org/weleadinlearning/transforrmationallead.

[15]. Haralambos, M. and Holborn, M. (1990) Sociology Themes and Perspectives, Suffolk: Harper Collins Publishers.

[16]. Kakabadse, A. and Kakabadse, N. (1999) Essence of leadership, London: Thomson learning.

[17]. Kennedy, C. [2007] Guide to the Management Gurus, U.K: Random House.

[18]. Lansberg, M. (2000). The tools of leadership, vision, inspiration and momentum, Great Britain: Harper Collins Business.

[19]. Leedy, P.D. (1997) Practical Research Planning and Design, New Jersey: Prentice Hall.

[20]. Lulee, S. [2011] Transformational Leadership; Leadership for Education.Retrieved20/04/2011from http://w.w.w.educause.edu/blog/susanlulee/TransformationalLeadership.

[21]. Mandaza, I. Ed (1987) Zimbabwe. The Political Economy of Transition.1980-1986. Harare: Jongwe Press.

[22]. Marturano, A. And Gosling, J. [2008] Leadership. The Key Concepts, New York: Routledge.

[23]. Mouton, J. (2004) How to succeed in your master's and doctoral studies, Pretoria: Van Schaik Publishers.

[24]. Nelson, J.L. Carlson, K. and Palonsky S.B. (1996) Critical issues in Education: a dialectic approach. The McGraw-Hill Company inc

[25]. Nziramasanga, C.T. [1999] Report of the Presidential Commission of Inquiry into Education and Training. Harare: Ministry of Education. Zimbabwe

[26]. Reading Guide. Book1. PhD Degree by Research Module 1: Research Methodology (2009) Prosperity Graduate Business School (PGBS) / NUST Randburg: Johannesburg [Unpublished]

[27]. Rehfeld, J.E. (1994) Alchemy of a leader. Combining Western and Japanese management skills to transform your company, New York: John Wiley and Sons, Inc.

[28]. Reynolds, D. and Cuttance, P. [1982] School Effectiveness Research Policy and Practice, London: Cassel.

[29]. Rukanda, M. et al (1997) Effective Management, Harare: Zebra Publications.

[30]. Sadle, P. (2003) Leadership, USA: Kogan Page Limited. 
[31]. SEDL Advancing Research, improving education. Leadership characteristics that facilitate school change. retrieved 01/11/2010 from mhtml: file//c:/documents and setting/

[32]. Senge, P. [1990] Fifth Discipline. Art and Practice of Learning Organisation, UK: Random House Ltd.

[33]. Simic, I. (1998). Transformational leadership. The key to successful management of transformational organizational changes. The scientific journal fact universities vol, No.6. 1998 p 49-55 retrieved 18/11/2010.

[34]. Smit, P.J. and Cronje de J. (1997). Management Principle, Cape Town: Creda Press.

[35]. Stone, B. and Parker, C. (2003) Developing Management Skills for Leadership, Prentice Hall: Glasgow School Press.

[36]. The Chronicle: 10 June 2009. Bulawayo

[37]. The Chronicle: 25 September 2009. Bulawayo

[38]. The Herald: 5 May 1995. Harare.

[39]. Thomas, J.R. and Nelson, J. R. (2001) Research Methods in Physical Activity, Australia: Human Kinetics.

[40]. Tuckman, B.W. (1994) Conducting Educational Research, New York: Harcourt Brace College Publishers

[41]. Zvogbo, R.G. [2004] The Organization and Administration of Primary and Secondary School Education, Mount Pleasant: ZOU. 